we did not detect the "s" which removed them from the turf in Chicago to the sidelines in Buckinghamshire.

Yours faithfully, Russell TƯTTLE

University of Chicago,

Department of Anthropology,

1126 East 59th Street,

Chicago, Illinois 60637

\section{Disaster Research}

SIR,-The London Technical Group is in the process of compiling a list of people engaged in research which could be of value to workers in the disaster field.

We would be grateful to hear from anyone doing relevant research in such fields as medicine, nutrition, engineering, sociology and so on.

Yours faithfully,

MARy ANNe BAKer

London Technical Group,

Research Institutes Working Party,

35 a Brackenbury Road,

London W6 OBE

\title{
Obituary
}

\section{Professor J. J. Weiss}

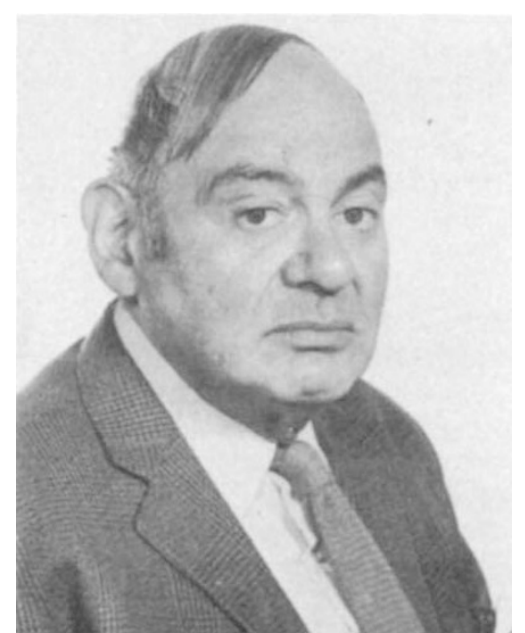

Joseph Joshua WeISS, Emeritus Professor of Radiation Chemistry at the University of Newcastle upon Tyne, died on April 9, 1972, at his home in Newcastle.

Born in Austria in 1905, Weiss studied at the Technische Hochschule in Vienna, where he obtained his doctorate. After spending two years (1928-30) at the Textile Institute in Sorau he moved to Germany to become assistant to Fritz Haber at the KaiserWilhelm Institut für Physikalische Chemie und Elektrochemie, Berlin. The short period spent with Haber was a very important one; not only was Weiss's scientific career essentially moulded during this time, but it also provided an opportunity for him to establish personal contact with many of the great figures in the physical and mathematical sciences. A scientific product of this period is the well-known Haber-Weiss mechanism for the catalytic decomposition of hydrogen peroxide by ferrous ions; involving, as it does, the intermediate production of free radicals it is a milestone in the history of studies of free-radical reactions in solution.
The political atmosphere in Germany in the early thirties affected many of the scientific institutions so that in 1933 Haber, accompanied by Weiss (his last assistant), left Berlin to take up a post at the University of Cambridge. After Haber's death, which occurred soon afterwards, Weiss moved to University College, London, carrying out a research programme and obtaining a $\mathrm{PhD}$ degree. Ideas on the role of electrontransfer processes in the mechanisms of photochemical and thermal reactions laid the foundation for the research work during the following years. Such processes were postulated to occur in the quenching of fluorescence, in dyesensitized reactions and in chemiluminescence. Weiss discovered the role of positive hydrocarbon ions in systems containing aromatic molecules and polycyclic hydrocarbons; this particular work led to research on the formation and structure of molecular complexes, which were postulated to be charge-transfer complexes. Weiss's long association with Newcastle upon Tyne began in 1937 with an appointment to a demonstratorship in King's College, University of Durham (now the University of Newcastle upon Tyne). In 1942, Weiss became interested in the theory of chromatography and published the first rather detailed mathematical theory for equilibrium conditions. It was at this stage, however, that he first began his researches into the chemical effects of ionizing radiations, particularly in solutions. As a consequence of the many significant contributions which then followed, Weiss may be rightly described as one of the fathers of the now extensive field of radiation chemistry. Thus, in 1944, he proposed that chemical effects in aqueous solutions can be accounted for by $\mathrm{H}$ atoms and $\mathrm{OH}$ radicals, this freeradical theory being elaborated in a large number of systems, including solutions of substances of biological interest. The implications of these ideas to radio- biology were pointed out, allowing a new avenue of approach in this important area. The many productive years which followed led to Weiss's eventual promotion to a professorship and to the establishment of the Laboratory of Radiation Chemistry at Newcastle.

Professor Weiss was one of the pioneers in the field leading to the discovery of the hydrated electron as an entity in irradiated aqueous solutions. $\mathrm{He}$ was particularly interested in the exact physical state of trapped electrons and was recently working on this problem again.

On the occasion of his sixtieth birthday, and as a tribute to his many achievements, an International Conference on Radiation Chemistry and Photochemistry was held at the University of Newcastle upon Tyne. International recognition has led to the conferment of a honorary degree by the Technical University of Berlin (1968), the award of the Marie Curie Medal of the Institut du Radium (1970), and, recently, to the establishment of the Weiss Medal by the Association for Radiation Research. On retirement from his chair in Newcastle, an issue of the International Journal for Radiation Physics and Chemistry was dedicated to him "in appreciation of his exceptional contributions to radiation and photochemistry". Latterly, Professor Weiss was conducting research programmes at the Max-Planck Institut für Kohlenforschung, Mulheim, and at the Paterson Laboratories, Christie Hospital and Holt Radium Institute, Manchester; such activity in his official retirement was characteristic of his lifelong dedication to science.

Professor Weiss will be remembered not only for his research work and his stimulating presence at scientific gatherings, but also, with gratitude, by the many pupils and colleagues who have benefited from his wide-ranging knowledge of science and of seientists. 